\title{
Demografía y SARS-CoV-2
}

\section{Demography and SARS-CoV-2}

\author{
Manuel Ordorica-Mellado \\ Centro de Estudios Demográficos, Urbanos y Ambientales \\ de El Colegio de México, México
}

\section{Resumen}

El objetivo de este artículo es presentar un breve recuento histórico de cómo los seres humanos han ido descubriendo el camino para enfrentar a los microorganismos. Mostrar como el nacimiento de la demografía está ligado a las pandemias y a las muertes que ocurrían en Inglaterra en el siglo XVII con los trabajos de John Graunt. Además, intenta mostrar la dificultad que tenemos las personas para entender el crecimiento exponencial. Asimismo, se presenta un análisis gráfico de la evolución de los contagios de las defunciones por Covid-19 y del Índice básico de reproducción para el caso de México, desde que inicio la pandemia hasta finales del 2020, para luego terminar con un conjunto de conclusiones.

Palabras clave: Demografía, SARS-CoV-2, defunciones por Covid-19, Índice básico de reproducción.

\section{Abstract}

The objective of this article is to present a brief historical account of how human beings have discovered the way to confront microorganisms. Show how the birth of demography is linked to the pandemics and deaths that occurred in England in the seventeenth century with the works of John Graunt. It also tries to show the difficulty that people have to understand exponential growth. Likewise, a graphic analysis of the evolution of infections, deaths from Covid-19 and the basic reproduction index for the case of Mexico is presented, from the beginning of the pandemic until the end of 2020, and then ending with a set of conclusions.

Keywords: Demography, SARS-CoV-2, deaths from Covid-19, basic index of reproduction. 


\section{INTRODUCCIÓN}

H

a sido difícil escribir este artículo relativo a la pandemia del SARS-CoV-2 que contuviera una serie de datos actualizados sobre la dinámica de los contagios y las muertes por el coronavirus en México. La velocidad vertiginosa a la que ocurren los eventos, hace que las cifras se hagan obsoletas muy rápidamente.

El acelerado crecimiento demográfico en las ciudades y el consumo de alimentos animales exóticos en varios lugares de esas ciudades, con poca higiene para tratar esos alimentos, con virus desconocidos para nuestro sistema inmunológico, con capacidad de mutar para adaptarse al cuerpo humano, han hecho que se produzcan enfermedades como el SARS-CoV-2, hasta hace poco desconocida en su relación con las personas. Ante esta nueva enfermedad, el sistema inmunológico de los seres humanos no ha estado preparado para enfrentarse a este nuevo germen, por lo que no hemos generado anticuerpos para enfrentarnos a él. Lo ocurrido en el mercado de la ciudad de Wuhan en China es tan solo un ejemplo de lo que puede ocurrir en otras zonas del mundo, ya sea que fuere el murciélago, el transmisor original y el pangolín, el transmisor a los seres humanos, o cualquier otra variedad de virus de animales que se encuentren en lugares insalubres. Lo que queda claro, es que estas pandemias ocurren cada vez con mayor frecuencia debido a los problemas demográficos y ambientales, aunado a que vivimos en un planeta globalizado que facilita el contagio entre los individuos.

Nuestros gobiernos han apoyado de manera insignificante la investigación científica; es inadmisible que en nuestro país no se esté elaborando una vacuna propia para enfrentar rápido al coronavirus. Ya no podemos depender más de lo que otros países hacen para avanzar en el conocimiento científico. ¿Qué ocurriría si otros países no hubieran desarrollado la vacuna contra el SARS-CoV-2? Nos resignaríamos a que una tercera o cuarta parte de nuestros habitantes falleciera por la enfermedad, como ocurrió en la ciudad de Londres en el siglo XVII cuando la peste aniquiló a la población de esa ciudad y sólo dejaron de morir los londinenses cuando se llegó a la inmunidad de rebaño.

En 2015, Bill Gates alertó al mundo sobre el riesgo de un brote muy contagioso y letal de la gripe. Si bien es cierto que el coronavirus no es un virus caracterizado por una elevada letalidad, su aparición ha puesto en jaque a la humanidad. Señalaba Bill Gates que algo que podría matar a más de diez millones de personas en las próximas décadas, sería un virus muy 
infeccioso, más que una guerra: no serían misiles, sino microbios; pronosticó que un ataque de estas características podría dejar hasta 30 millones de muertos en seis meses. ${ }^{1}$ Señalaba que muchos fondos económicos se había orientado a mejorar el poder de las armas y poco se había asignado a enfrentar los problemas que se podrían derivar de los virus y las bacterias.

Antes, en 2003, se publicó el libro Six Modern Plagues and How We Are Causing Them de Mark Jerome Walters en el que se señalaba lo siguiente: "Muchos epidemiólogos advierten que es solo cuestión de tiempo para que otra epidemia de la magnitud del brote de "“"influenza española"” de los años 1918 y 1919, o la pandemia actual del VIH/sida, recorra todo el mundo" (Jerome Walters, 2011). No obstante, estos avisos, no hicimos caso para enfrentar estas epidemias altamente letales. Sólo actuamos cuando el problema lo tenemos encima.

Es cierto que el coronavirus nos tomó por sorpresa a la población y a los gobernantes en 2020, aunque como mencioné los científicos ya nos habían alertado. Tuvimos un aviso con la pandemia de influenza H1N1 ocurrida en 2009. Este tipo de catástrofes ocurren cuando el ser humano invade los límites territoriales de otros seres vivientes en la Tierra. Queda claro que no conocemos a la inmensa y gran variedad de seres que residen en el planeta y que pueden llevarnos a la extinción. Nunca imaginamos que se presentaría una catástrofe planetaria de este tipo, semejante a la ocurrida en 1918 con la "influenza española". Si bien es cierto que siempre hay que aprender de la historia, queda claro que las personas sólo aprendemos de nuestra propia experiencia y no tomamos en cuenta la experiencia de los demás. Además, tenemos un pensamiento mágico en el que imaginamos que los contagios y las muertes no nos van a ocurrir a nosotros. Que lo malo sólo le ocurre a los demás. Hoy más que nunca es cierto el dicho: Nadie aprende en cabeza ajena. Desgraciadamente quienes tuvieron una experiencia similar a la actual, los que vivieron hace un siglo, durante la "influenza española", la mayor parte ya fallecieron, tendrían más de 100 años de edad, entre ellos pudiera ser que se encontraran vivos, nuestros padres y abuelos o nuestras madres y abuelas. A quienes les dio "influenza española" hace un siglo y sobrevivieron, su sistema inmunológico seguramente los mantuvo fuertes a los ataques de rebrotes posteriores. La experiencia personal de haber convivido con mi madre, que siendo una niña fue contagiada por el virus en un rebrote de la "influenza española", me permitió conocer las acciones cotidianas que cada individuo debe emprender

\footnotetext{
${ }^{1}$ Gates, Bill (2020). El fundador de Microsoft avisó en un video que el Mundo no estaba preparado para una enfermedad como el coronavirus.
} 
para no ser contagiado. No es posible dejar a la población que decida sobre sus actividades cotidianas durante la pandemia. El Estado debe de actuar con decisión ante una enfermedad que mata sin piedad. La democracia es válida mientras no se afecte la vida de los demás. Hay decisiones que no se les pueden dejar a la población, porque pueden atentar contra la vida de otros individuos sin saberlo.

Debimos de haber actuado más rápido a partir de la experiencia de los países europeos y asiáticos. Tuvimos un tiempo de ventaja al principio para que nos hubiéramos aislado y no llegar a tener las cifras de muertes y contagios tan elevada. Ante el desconocimiento de gran parte de la población sobre el significado de una enfermedad tan contagiosa como el SARS-CoV-2, las autoridades debieron de tomar medidas más estrictas para que la población se mantuviera en casa. Actuar al inicio de la pandemia de Covid-19 de manera más enérgica no nos hubiera llevado a niveles de mortalidad tan elevados como los observados.

Además, en este 2020, ha quedado clara la falta de conocimientos de tipo matemático relativa al crecimiento exponencial y logístico de los contagios y de las muertes por parte de quienes gobiernan los países y de la gran mayoría de sus ciudadanos. No entendemos lo que tiene un ritmo diferente al que estamos acostumbrados y tampoco entendemos el infinito en el cosmos o el infinito en lo minúsculo, tal es el caso de la partícula de dios.

Un gran problema que tenemos los seres humanos es nuestra dificultad de entender el crecimiento exponencial. No podemos imaginarnos números muy grandes, ni números muy pequeños, ni lo tremendamente lejano, $\mathrm{y}$ ni lo que se multiplica a gran velocidad. Este es un síndrome que prácticamente todos padecemos. Entendemos lo que sigue el ritmo de nuestra vida.

Para cruzar la parte más ancha de nuestra Galaxia, la Vía Láctea, necesitaríamos aproximadamente un millón de años luz, lo que quiere decir que viajando a la velocidad de la luz tardaríamos un millón de años en atravesarla. Quiere decir que eso nunca lo lograremos, nunca podríamos hacer ese viaje por nuestra Vía Láctea. Quizá es por eso que se encuentra fuera de nuestras posibilidades, es como si no existiera. Apenas estamos descubriendo los rincones de nuestro sistema solar. Carl Sagan (1998: 11) escribe que posiblemente haya 100,000 millones de galaxias y 10,000 trillones de estrellas. Para apreciar lo que significa un trillón, imaginemos que tuviéramos que contarlo. Si empezáramos desde el uno hasta un trillón, de a uno por segundo, tardaríamos 32,000 millones de años, más que la edad del Universo (Sagan, 1998: 17). Son números que tampoco entendemos. 
Ahora imaginemos lo casi invisible. Si tuviéramos una caja en forma de cubo, de 16 centímetros de lado, por 16 centímetros de ancho y por 16 centímetros de altura podría haber un trillón de coronavirus residiendo en ese lugar, considerando que cada uno de ellos mide 160 nanómetros. ${ }^{2}$ Poniéndolos codo con codo a cada uno de los coronavirus. Como el virus es tan pequeño, pensamos que no existe. Para apreciar la pequeñez de los virus, es posible señalar, en general, que los virus son de menor tamaño que las bacterias, lo pequeño de lo pequeño. Pueden ser vistos con los microscopios electrónicos más potentes.

Veamos lo que crece muy rápido a un ritmo exponencial a través del invento del ajedrez. El juego del ajedrez permite tener una inmensidad de jugadas a lo largo de la partida, lo que hace al juego muy atractivo, en el tablero de 64 casillas. En un juego aparentemente sencillo, de dos oponentes, se abren una gran posibilidad de movimientos para vencer al contrario. Para entender la velocidad del crecimiento exponencial, recordemos a Sissa, ciudadano de la India, quien fue el creador del ajedrez. Este juego lo invento Sissa para que el rey no estuviera triste y Sissa pensaba como podría consolarlo. El hijo del rey había muerto en una batalla, de ahí su tristeza. Se le ocurrió que podría inventar un juego que tratara sobre la guerra, pero un juego en el que no hubiera muertos. Un juego en el que la pieza más poderosa es la dama, la cual se puede mover a cualquier lugar del tablero muy rápidamente, pero se acaba el juego matando al rey, que solo puede moverse una casilla en cada tirada. Después de aprender a jugar el ajedrez, jugó muchas partidas. El rey estaba tan contento con Sissa que le dijo que pidiera lo que más quisiera. Soy muy rico y puedo darte lo que quieras. Te puedo dar oro, joyas, palacios, lo que quieras. Sissa le dijo al rey, sólo quiero un grano de trigo en la primera casilla del tablero de ajedrez; dos en la segunda; cuatro en la tercera; ocho en la cuarta; 16 en la quinta, 32 en la sexta, 64 en la séptima, etc. El rey reaccionó muy molesto, pensando que lo que había pedido Sissa era una ofensa, incluso el rey se sintió despreciado. Le dijo a sus súbditos de mala gana y molesto, por lo que había pedido Sissa, y en tono agresivo les dijo, tráiganle los sacos que pidió. Después de un rato largo, los matemáticos del reino le dijeron al rey que lo que había pedido Sissa era enormemente grande. El resultado fue 18.4 trillones de granos de trigo, cifra equivalente a la producción de trigo de todo el planeta por un milenio. El rey nunca se imaginó un número tan grande.

El crecimiento exponencial es engañoso, genera números elevados muy rápido. La evolución de los contagios acumulados por Covid-19 ha se-

\footnotetext{
${ }^{2}$ Un nanómetro es $10^{-9}$ metros.
} 
guido un crecimiento exponencial hasta que llegue al punto de inflexión, donde cambiará la tendencia y se convierta en una curva logística, la cual tiene una asíntota superior y también una asíntota inferior. Hago esta breve introducción debido a que el coronavirus, es muy pequeño, casi invisible y contagia a muchas personas en un tiempo breve. En pocas palabras quiere decir que no lo entendemos. Nuestra mente está adaptada a entender bien los modelos lineales. Los demógrafos en nuestros modelos multivariados relacionamos linealmente las variables, como por ejemplo, a mayor educación de la pareja, menor fecundidad o a mayor escolaridad de la mujer, menor tasa de mortalidad infantil. Cualquier relación que salga de ese patrón no la entendemos. Es más, hacemos transformaciones matemáticas para llevar el comportamiento a una relación lineal y así poder entenderlo. Otro ejemplo, que se lo debemos a William Brass, demógrafo inglés, es el uso del sistema logito, que permite analizar tablas de mortalidad y evaluar la calidad de los datos. El logito es una función logarítmica, es decir, una función que cambia la escala de las variables.

Hay una gran cantidad de ejemplos que nos hacen pensar en el crecimiento exponencial, como el siguiente: imaginemos que una planta que crece en cierto lago se duplica todos los días. Si se le dejara sin control cubriría el lago en 30 días. El dueño decide esperar a cortar la planta hasta cuando ésta haya cubierto la mitad del lago. ¿Cuándo lo debe hacer? ...... Un día antes. Muchos responderían que el día 15 en una respuesta lineal. Si el día 30 está cubierto todo el lago con la planta, el día 29 cubriría a la mitad, ya que sabemos que cada día se duplica.

Supongamos otro ejemplo; el paramecium caudatum, un protozoo que vive en agua dulce, en condiciones óptimas puede dividirse en dos cada seis horas ¿qué cifra habría al cabo de cuatro días? ..... Sería de 65,536. En poco tiempo se llegó a una cifra muy elevada.

Si los gobernantes hubieran entendido el crecimiento exponencial y hubieran hecho caso a los científicos de la necesidad de que todos y todas nos hubiéramos aislado por unas semanas al principio, no nos encontraríamos en la catástrofe de muertes por Covid. Pensamos que se iba a terminar la enfermedad por arte de magia.

Es importante reconocer a los pioneros en el campo de la bacteriología y la virología. En 1926 Paul de Kruif escribió el libro: "Los cazadores de microbios", en el que se describen las investigaciones de los grandes observadores de lo diminuto. Uno de ellos fue el holandés Antonio Von Leeuwenhoek, descubridor de lo invisible, quien en el último cuarto del siglo XVII se le despertó su interés por la fabricación de lentes y luego 
de microscopios, eso le permitió ser el primero en asomarse a un mundo no conocido, poblado de millones de especies de seres diminutos. Los veía moviéndose ágilmente con varios pies, se paraban, se movían como trompos, corrían. Examinaba todo lo que se le ponía en frente, gotas de lluvia, incluso hasta el sarro de las muelas. Hizo experimentos calentando agua a gran temperatura con esos bichos y observó que dejaban de pegar carreras. Luego enfriaba el agua y los bichejos no recobraban su energía. En una ocasión obtuvo una muestra de su boca y encontró a los microorganismos, y luego al otro día, después de tomar una taza de café bien caliente, encontró que no estaban los animalejos, habían muerto. Por cierto, siendo un niño, en una ocasión Antonio Von Leeuwenhoek le preguntó a su papá, ¿cuál es la causa de las paperas? El padre le contestó sabiamente: el culpable es un espíritu maligno de las paperas. Tuvo que hacer como que se lo creía, porque si no le tocaría una tunda. Era tan observador con sus microscopios que incluso llegó a ver el aparato bucal de una pulga. Valga la pena recordarlo ahora por lo que vamos a analizar (de Kruif, 2014). A partir de él vinieron otros científicos que ayudaron a establecer la relación entre microbios, virus y las enfermedades.

Todos estamos muy angustiados por la pandemia, pasan los meses y no se terminan los contagios, por lo que el objetivo de este trabajo es aproximarse, de ser posible, al momento de su fin, a través de un elemento: el valor de $\mathrm{R}_{0}$, que es el número reproductivo básico, por el cual se estima la velocidad con la que el Covid-19 puede propagarse. Por cierto, ya llegamos al año del primer contagio oficial de Covid. Los valores más elevados de son los del sarampión. Dicho índice puede variar entre 12 y 18 personas, lo que quiere decir que una persona puede contagiar a entre 12 y 18 personas. Ha sido muy importante haber encontrado la vacuna del sarampión porque el nivel de contagiosidad es muy elevado.

El número reproductivo básico en el caso del Covid-19 puede oscilar entre 1.5 y $3.5,{ }^{3}$ aunque estas cifras han ido cambiando con el tiempo, ahora que ya se conoce más la enfermedad. En síntesis, es el número promedio de casos nuevos que genera un caso dado a lo largo de un periodo infeccioso. Cuando $\mathrm{R}_{0}$ es menor que 1 , la infección desaparece. Cuando $\mathrm{R}_{0}$ es mayor a 1, la infección se propaga ampliamente; en la medida que $\mathrm{R}_{0}$ es más grande, es más difícil controlar la epidemia. $\mathrm{Si} \mathrm{R}_{0}$ es igual a uno, quiere decir que un infectado sólo podría infectar a otro. Este es un estado estacionario.

\footnotetext{
${ }^{3}$ The Conversation, CC-BY-ND
} 
Los orígenes del indicador se remontan al trabajo de Alfred Lotka en 1939 (Lotka, 1969). Este concepto es análogo y tiene el mismo símbolo que el indicador que los demógrafos usamos para calcular el número de hijas que van a sustituir a una madre, el cual se denomina: tasa neta de reproducción. La tasa neta de reproducción es el número de hijas que van a sustituir a una madre. Cuando la tasa neta de reproducción es igual a 1, se dice que la población se encuentra en el nivel de reemplazo y su tasa de crecimiento demográfico sería igual a cero. En este caso la población se mantendrá con el mismo número de habitantes a lo largo de los años. Una diferencia importante en términos numéricos en la aplicación a la demografía y la aplicación en los contagios por el coronavirus, es que mientras en el primer caso una o más hijas pueden sustituir a una madre en varios años, en el caso de la enfermedad por el Covid, una persona puede contagiar a más de una en pocos días. El concepto es semejante, la velocidad es muy diferente.

\section{El NACIMIENTo de LA deMogRAFíA}

Para muchos científicos sociales, la Demografía nació a partir de las muertes ocurridas en las epidemias. Se originó con John Graunt en 1662 con la publicación sobre los Boletines de la Mortalidad (Graunt, 1662). Por cierto, Graunt no era un científico, era un próspero comerciante de tejidos establecido en Londres. Esos boletines semanales cuya publicación se remonta a principios del siglo XVI, daban todos los martes la relación de las defunciones y a veces de los nacimientos registrados en las diferentes parroquias de Londres. Tuvieron que pasar muchos años para que los ojos y la mente de un ser humano los utilizara para bien de las personas. A partir de 1629 se indicaban las causas de las defunciones, tal y como podían ser interpretadas en esa época por personas con pocos conocimientos sobre la materia. Para Graunt la lista de estadísticas no era un juego, más bien le permitieron ver los factores sociales ligados a la mortalidad. Para muchos que recibían los boletines, que no tenían el interés científico de Graunt, sólo les servían para poder hacer de estos un tema de conversación. Para muchos, simple y sencillamente eran unos datos curiosos. Estas listas representaban un excelente oxímetro o termómetro de la epidemia, ya que medían la dinámica de los fallecimientos debido a la peste. Esta ciencia, la Demografía, nació en momentos en los que la peste rondaba en Londres. La bacteria Yersinia pestis fue el agente de la Gran Plaga en Londres (1665-1666) que produjo la muerte de casi la cuarta parte de la población londinense. La población de Londres era de 400 mil habitantes y la peste mató a la cuarta parte de esa 
población (Reinhard y Armengaud, 1966). Esta enfermedad ya había atacado a Londres dos veces en el siglo XVII. La información de los boletines permitió observar el avance y retroceso de la enfermedad y para los ricos, poder decidir sobre la posibilidad de alejarse del lugar donde los contagios eran elevados. Muchos se movían hacia sus casas de campo a las afueras de la ciudad, para no cruzarse con la peste. El gran acierto de Graunt fue analizar por primera vez los famosos boletines de la mortalidad. A nuestro juicio estos análisis representan una nueva forma de lo que hoy podemos llamar Estadística, Epidemiología o Demografía. Era una nueva forma de estudiar la vida y la muerte.

Esto no es nuevo, a lo largo de los siglos y desde el lado religioso se ha hablado de los Cuatro Jinetes del Apocalipsis, quienes llegarán para destruir el planeta. La imagen bíblica de los cuatro jinetes del Apocalipsis: la Guerra, el Hambre, la Peste y la Muerte tienen nueva cara y más compleja. Muchos científicos se preguntan si el SARS-CoV-2 se trata de un simple virus o es un síntoma de algo más profundo, que hace evidente un mundo cada vez más globalizado y conectado, y en consecuencia más frágil y volátil y con posibilidades de que este tipo de pandemias se vean cada vez en forma más frecuente. Estamos viendo como la pandemia puede hacer metástasis en otros aspectos vitales de los países, como la estabilidad económica y la geopolítica, lo cual podría convertirse en una catástrofe sin precedentes. Podemos decir que esta pandemia pudiera no ser la causa directa de una catástrofe planetaria, como el iceberg que partió el Titanic, y que nos señala que estamos surcando un mar peligroso que tiene cada vez más icebergs, ligados a la destrucción de nuestro medio ambiente y la vida en la Tierra.

En la obra de Malthus aparecen también las epidemias. Una de las teorías demográficas más comentada en la historia de los estudios de población es la realizada por Thomas Malthus, en su "Ensayo sobre el Principio de la Población" elaborado en 1798, señalaba que la población podía aumentar mediante un crecimiento geométrico, como 1, 2, 4, 8, 16, 32, etc. y los alimentos mediante una progresión aritmética, como 1, 2, 3, 4, 5, 6, etc. Sin duda que a este ritmo llegaría un momento en que los medios de subsistencia no alcanzarían para alimentar a todos los habitantes. Malthus ha sido muy cuestionado ya que no tomó en cuenta el avance tecnológico, sin embargo, su teoría en la actualidad continúa discutiéndose y ahora vuelve a analizarse a partir de la pandemia del Covid-19 y del muy rápido crecimiento demográfico de las ciudades, que es donde el coronavirus se ha ensañado. En su ensayo Malthus escribía sobre los obstáculos positivos 
que se oponen al crecimiento demográfico, que son todos aquellos que contribuyen a reducir la duración de la vida. En este grupo incluía a la pobreza extrema, la vida de las grandes ciudades, las guerras, el hambre, las epidemias y las pestes. Esta enfermedad, la peste, era tan letal que para Malthus merecía un apartado especial en sus análisis.

Malthus decía:

Estudiando las pestes y las épocas enfermizas ... de un periodo de aumento rápido de la población, es imposible no dejarse impresionar por la idea de que el número de habitantes había excedido en esos casos de la cantidad de alimentos y de las facilidades necesarias para conservarlos en buena salud (Malthus, 1977).

No todo es malo en los aislamientos y confinamientos. Durante las epidemias de peste en el siglo XVII se dieron importantes avances en la ciencia. Isaac Newton descubrió, entre otras cosas, la ley de la gravitación universal y escribió las bases del Cálculo integral y diferencial, desarrolló sus teorías sobre óptica durante el aislamiento por la peste en 1665. Se dice que William Shakespeare en la cuarentena de 1606, durante el brote de peste, creó algunas de sus grandes obras trágicas: El rey Lear, Macbeth, y Antonio y Cleopatra (Ventura, 2020). Hoy, como antes, las personas nos hemos tenido que transformar y trabajar utilizando los medios tecnológicos más avanzados. Hemos aprendido mucho sobre los virus y las bacterias. Nuestras relaciones con los demás se han transformado. Las reuniones familiares, los cursos, las conferencias, los congresos se hacen por línea. Lo que también es cierto, es que deberíamos de reflexionar sobre cuál es el fin de los seres humanos en la Tierra. No podremos mantenernos en esta situación de manera perenne.

La peste generó una creatividad inmensa en escritores y científicos. Los horripilantes sucesos asociados a la peste ocurrida entre 1664 y 1666 en Londres llevó a grandes novelistas como Daniel Defoe (1722) en su "Diario del año de la peste" a que escribiera una de las obras cumbre de la literatura inglesa en un espeluznante relato en el que describe los horrores que ocurrieron durante la epidemia de peste que asoló a Londres y sus alrededores. Defoe siendo un niño se convierte en testigo de los comportamientos humanos de mayor heroísmo, pero también los más mezquinos: sirvientes que cuidan abnegadamente a sus amos, padres que abandonan a sus hijos infectados, casas tapiadas con los enfermos adentro, los acaudalados huyendo a sus casas de campo y extendiendo la epidemia más allá de las murallas de la ciudad. 


\section{La “influenZa esPañola” en MéXico}

Según los analistas, en México perecieron por la "influenza española" entre 300 mil y 500 mil mexicanos durante el otoño de 1918. México tenía en esa fecha una población de alrededor de 14 millones, lo que significa que murió 3.5 por ciento de la población mexicana, si tomamos el número de 500 mil muertes como correcto. Si ese porcentaje se presentara hoy con la enfermedad del Covid-19, podrían morir casi 4.5 millones de mexicanos. Hoy México tiene 128 millones de habitantes. Sólo para mostrar la terrible letalidad de la "influenza española" de hace un siglo.

Evitar conglomeraciones. No usar platos o toallas empleadas por otras personas a menos de que hayan sido previamente esterilizadas en agua hirviendo. No poner la boca en la bocina del teléfono. Evitar cambios bruscos de temperatura. Caminar en vez de usar el transporte cuando no se tenga que ir muy lejos. Lavarse la cara y las manos al llegar a la casa y cambiar de ropa, si fuere posible antes de estar entre los miembros de la familia. Además, no saludar de mano ni de beso, ventilar las habitaciones y taparse con un pañuelo al toser o estornudar (Arellano, 2020).

Al poner esta cita, pareciera que me estoy refiriendo a lo que ocurre hoy, pero en realidad no me estoy refiriendo a la actualidad, estas son las recomendaciones que hicieron las autoridades mexicanas de salud en 1918, las cuales son muy parecidas a las que hoy se hacen respecto al Covid-19. Algunas otras acciones tomadas en esa época fueron las siguientes: los barcos detectados con casos de "influenza española" se pusieron en cuarentena. También se ordenó, como ahora, el cierre de teatros, iglesias, restaurantes, y otros lugares de elevada concentración poblacional (Arellano, 2020).

Durante la pandemia de 1918, los fallecimientos diarios de cientos de personas ocasionaron que se saturaran los cementerios. En algunas partes del país se autorizó el entierro en fosas comunes. Los acelerados niveles de la mortalidad por la influenza ocasionaron que muchos ataúdes permanecieran en las calles esperando que los sepultaran. En esta pandemia murieron principalmente los adultos jóvenes y en su mayoría mujeres (Arellano, 2020). Es importante dejar en claro que no es lo mismo tratar una enfermedad infecciosa en México con 14 millones de habitantes en 1918 que con una población en 2020 casi 10 veces mayor y con una concentración muy elevada en las grandes ciudades. Hoy la enfermedad, de tres personas que mata, dos son hombres y una es mujer.

La "influenza española" mató a 50 millones de personas en el planeta en 1918, cuando el Mundo tenía 1,825 millones de habitantes. Esto quiere 
decir que mató a 2.7 por ciento de la población total. La Tierra tenía en 2020, 7,625 millones de individuos; si muriera 2.7 por ciento de la población mundial por coronavirus, fallecerían casi 206 millones de personas. Queda claro que la "influenza española" ha sido la enfermedad global más letal hasta hoy en la historia de la humanidad.

\section{Matemáticas PaRa obSERVAR al CORONAVirus}

Sea el número de contagios por Covid-19 en el tiempo, función que hemos visto que hasta hoy sigue un crecimiento exponencial en México.

$$
\text { Dividamos } \frac{C(t)}{C(t-T)}=\frac{C(0) e^{r t}}{C(0) e^{r(t-T)}}=e^{r T} \ldots
$$

$T$ es el tiempo medio en que una persona contagia a otras.

Sea el número reproductivo básico, y como ya dijimos muestra la velocidad a la que una enfermedad puede propagarse. Se sabe que $\mathrm{R}_{0}=\mathrm{e}^{\mathrm{rT}}$ (Lotka, 1969) lo que quiere decir que una persona contagia a $R_{0}$ personas en un tiempo promedio igual a $T$. Si sustituimos $\mathrm{R}_{0}=\mathrm{e}^{\mathrm{rT}}$ en (1) se tiene lo siguiente:

$$
\frac{C(t)}{C(t-T)}=R_{0} \ldots
$$

Si dividimos el tiempo de contagios en el tiempo entre los contagios en el tiempo obtenemos una estimación del número reproductivo básico o nivel de contagiosidad. ¿Qué valor tiene T? Este es un parámetro que están analizando los epidemiólogos y sobre el que todavía hace falta más investigación en el caso del Covid-19. Voy a suponer que el valor de $T$ podría ser de una semana, bajo el siguiente razonamiento:

1. A partir de una muestra, con base en los datos abiertos del Sector Salud, se encuentra que una persona, en promedio, entre el momento de los síntomas y el ingreso por Covid-19 a un centro hospitalario puede variar entre cuatro y cinco días, aunque puede ser menor, por lo que durante este tiempo pudo haber contagiado a uno o a varios individuos.

2. La mediana del periodo de incubación, que es el tiempo entre el instante que una persona contrae el virus hasta el comienzo de los síntomas, se estima de cinco a seis días, ${ }^{4}$ periodo que podría ser activo en el contagio del Covid-19.

\footnotetext{
${ }^{4}$ Ministerio de Sanidad. Información científica-técnica. Enfermedad por coronavirus, Covid-19; España. Actualización 2 de junio, 2020, p. 7.
} 
3. En nuestro país, los domingos y los lunes, las autoridades de salud presentan números más pequeños en las cifras de contagios, debido a que no se hace un registro completo de los datos en esos días de la semana. Al dividir los contagios en un día de la semana, respecto a los ocurridos exactamente una semana antes, se suaviza el error de la mala declaración de los datos obtenidos los fines de semana.

4. Este índice de reproducción básico no cambia significativamente para valores alrededor de siete.

Es importante observar en la Figura 1 que para $\mathrm{T}=7$, la dinámica de desciende de manera continua, acercándose al valor de uno, que es el objetivo central para eliminar al virus. Se presentan oscilaciones del indicador explicadas por la fuente de datos que registra su ocurrencia, en algunos casos, en forma tardía, una vez que se confirma la enfermedad por Covid-19. A mediados de abril en 2020 se presentó el pico del número reproductivo. Llama la atención que el valor de $R_{0}$ tuvo su máximo alrededor de dos, lo que quiere decir que las decisiones tomadas fueron correctas para que no se elevara en forma desmedida el número de contagios y muertes a cifras muy elevadas. En otros lugares del mundo el valor de $R_{0}$ por Covid-19 llegó a estar en casi seis al principio de la pandemia. Los mensajes relativos a "Susana distancia" cumplieron su objetivo, pero han sido insuficientes a lo largo del periodo. Muchas personas no respetan las reglas que la autoridad impone respecto al SARS-CoV-2.

En la Figura 1 es posible observar el descenso en el índice básico de reproducción para $T=7$. Podemos ver los valores máximos en el mes de marzo de 2020, cercanos a dos, después se mantiene constante y luego empieza un leve descenso sin llegar a 1.5.

En la Figura 2 se observa como la curva de contagios se reduce a finales de julio y principios de agosto, para luego incrementarse nuevamente a finales de septiembre y principios de octubre. Este podría considerarse un primer rebrote. El índice de reproducción básico lo deberemos de seguir observando diariamente, así como cuando tomamos la fiebre a un enfermo; es el termómetro para saber cómo va México en esta pandemia.

No obstante, estos escenarios positivos sobre la contagiosidad del Covid-19, es posible observar en la Figura 3 que la evolución de las defunciones siguió un crecimiento exponencial hasta finales del mes de julio y a partir de esa fecha empezó a descender, para luego volver a incrementarse a principio de octubre. Estamos en un momento en el que se tiene que ser estricto con las medidas que la autoridad ha señalado, porque la pandemia no está controlada. 
Figura 1: E.U.M: Índice básico de reproducción del SARS-COV-2, tomado con $\mathrm{T}$ igual a siete días

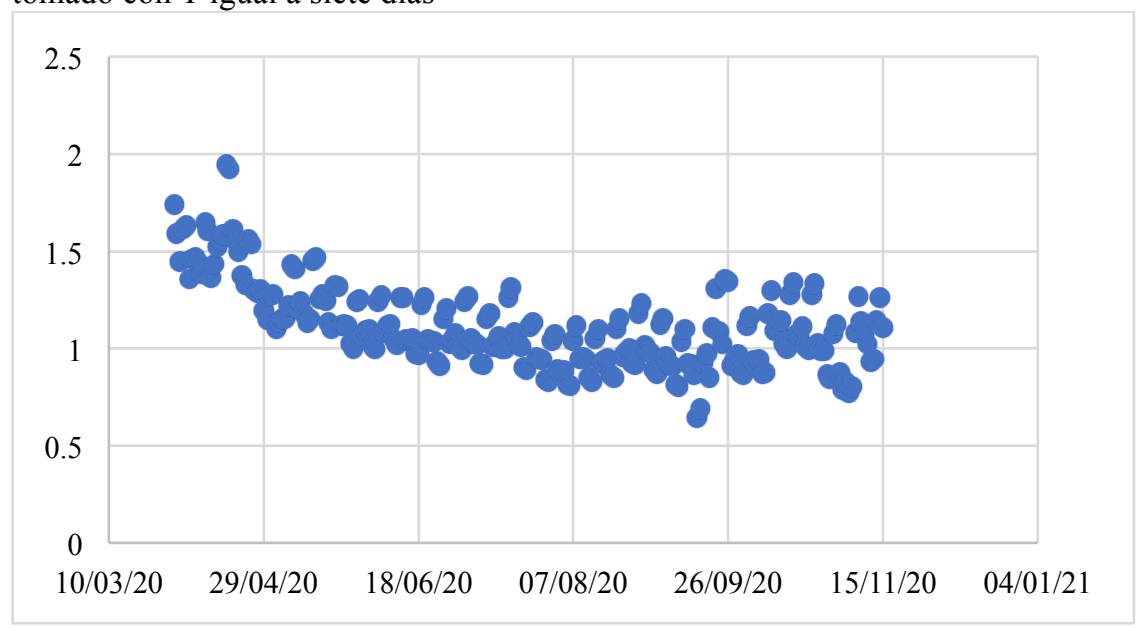

Cálculos propios.

Fuente: Secretaría de Salud.

Los contagios y las muertes relacionados a esta enfermedad se han presentado en forma desigual en la población. Las muertes por coronavirus se han concentrado principalmente en la población de mayor edad y en gran medida en los hombres; de cada tres muertes, una es mujer y dos son hombres. También las muertes se han concentrado en las áreas más densamente pobladas. Al 10 de diciembre de 2020, la ciudad de México y el Estado de México tenían 28 por ciento de los fallecimientos del país por SARS-CoV-2, es decir, poco más de la cuarta parte del total. Diez estados contaban en esa fecha con 60 por ciento de todos los decesos: Ciudad de México, Estado de México, Nuevo León, Guanajuato, Sonora, Coahuila, Jalisco, Puebla, Veracruz y Tabasco. La desigual distribución de la población en el territorio ha sido un factor clave, tanto en la multiplicación de los contagios como en las muertes.

Es verdad es que el coronavirus se ha ensañado en el mundo con la población en edades avanzadas. En Italia, por ejemplo, el máximo del porcentaje de decesos se presentó en las edades de 80 a 89 años, y en México el máximo se presenta en el grupo de edades de 60 a 69; le sigue muy de cerca el porcentaje de muertes del grupo de 50 a 59 años. En nuestro país las muertes por Covid-19 del grupo de edades de 40 a 49 años, en números absolutos es casi igual al de 70 a 79 años, claro está, la población de 40 a 49 años es mayor a la de 70 a 79 años. 
Demografía y SARS-COV-2 / M. ORDORICA MELLADO

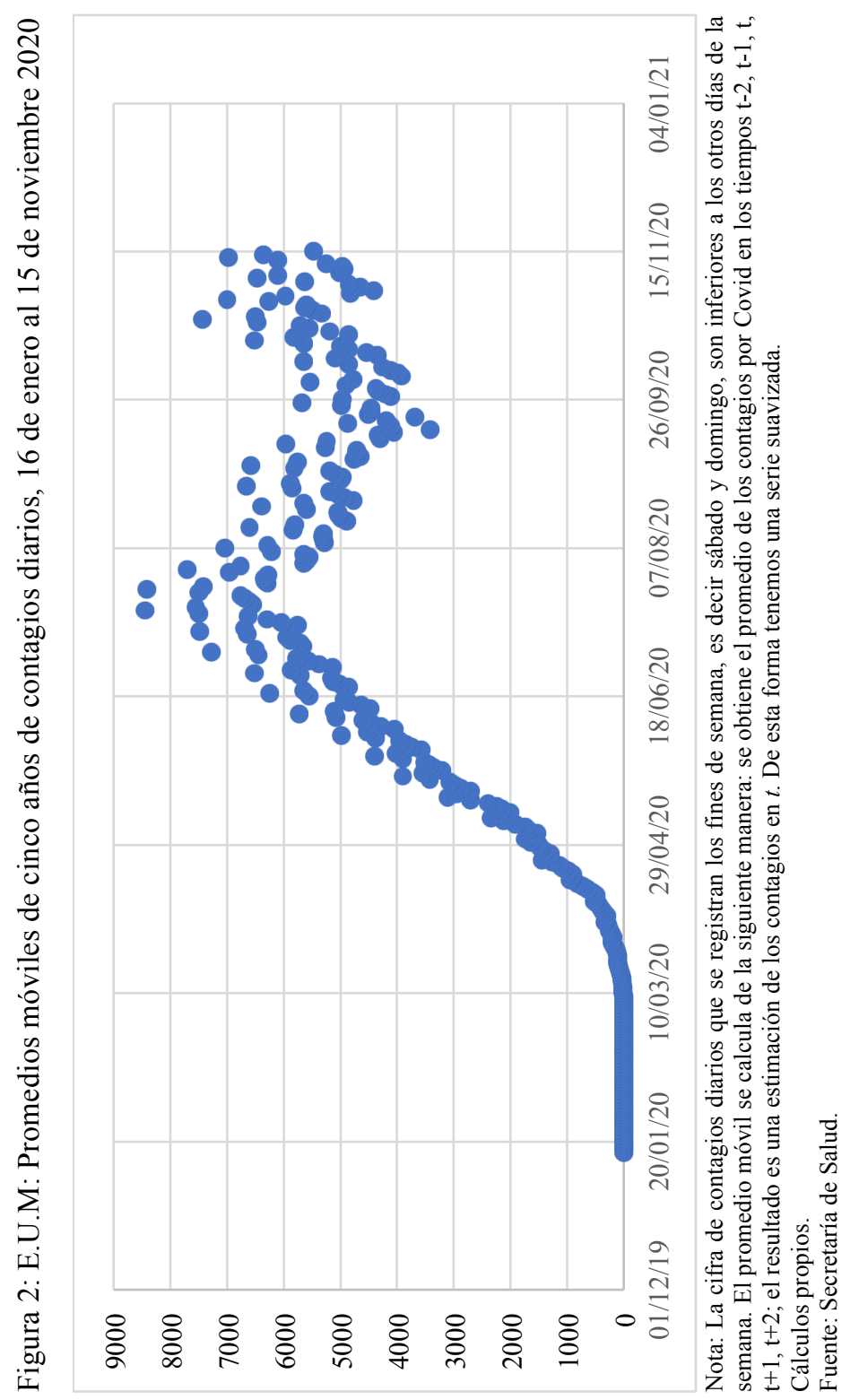


Figura 3: E.U.M: Promedio móviles de cinco años de las defunciones por Covid-19

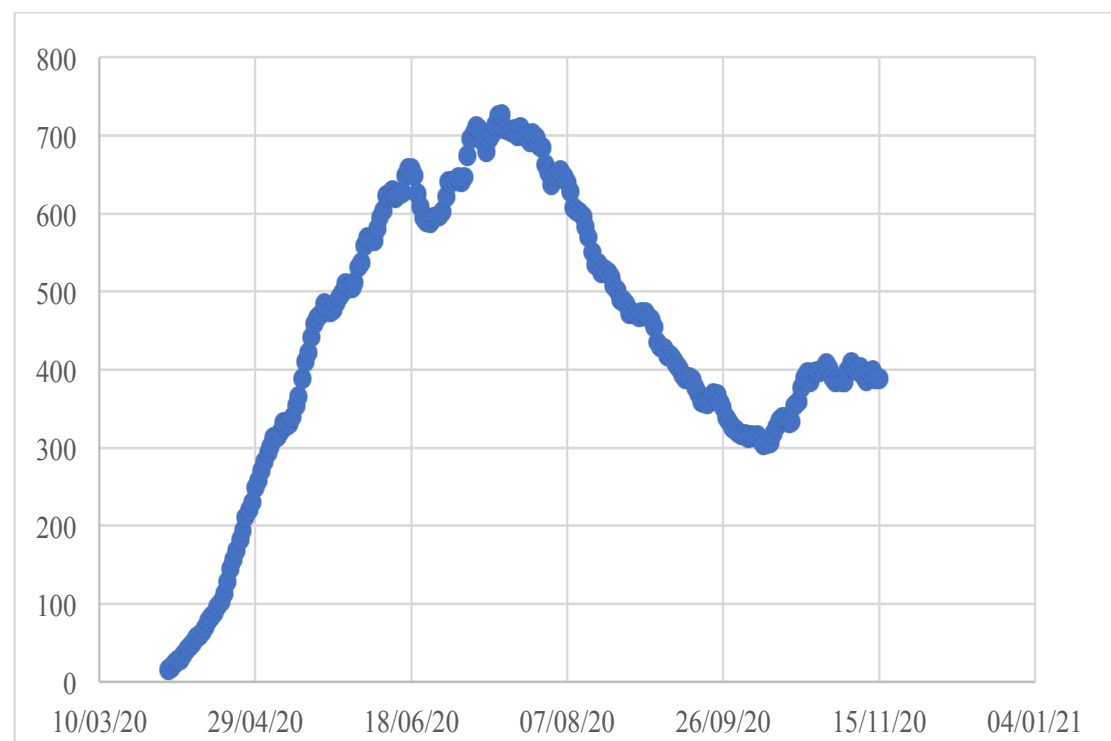

Nota: La cifra de defunciones diarias por Covid-19 que se registran los fines de semana, es decir sábado y domingo, son inferiores a las de los otros días de la semana. El promedio móvil se calcula de la siguiente manera: se obtiene el promedio de las defunciones por Covid en los tiempos $\mathrm{t}-2, \mathrm{t}-1, \mathrm{t}, \mathrm{t}+1, \mathrm{t}+2$; el resultado es una estimación de las defunciones en $t$. De esta forma tenemos una serie suavizada.

Cálculos propios.

Fuente: Secretaría de Salud.

Un elemento importante en las muertes y contagios por Covid es el proceso de envejecimiento de la población en edades avanzadas. El porcentaje de población de 65 años o más en México es de 7.6 por ciento, mientras que en Italia es de 23.3 por ciento y en España de 20 por ciento. Italia tiene un porcentaje de población de 65 años o más, tres veces mayor al de México. La edad mediana, que es la que parte en dos a la distribución por edades, es de 29 años en México, de 47 en Italia y de 45 años en España.

La población de la zona metropolitana de la ciudad de México, con 22.5 millones de personas, con casi la quinta parte de la población del país, con una densidad demográfica de alrededor de 2,600 habitantes por kilómetro cuadrado, con una población por debajo del reemplazo (el número promedio de hijos por mujer es de 1.5), con una esperanza de vida al nacer de 77 años y con un acelerado proceso de envejecimiento demográfico, superior al resto del país, se ha vuelto el lugar más afectado por este virus. Poblada, densa y envejecida demográficamente es una tercia que pone a la zona metropolitana de la ciudad de México, ante el Covid, en muy alto riesgo. 
Ante esta tercia de elementos demográficos los países han salido adelante. Japón hasta finales de diciembre tenía menos de tres mil muertes, aun teniendo una elevada densidad poblacional de 346.9 personas por kilómetro cuadrado. México sólo tiene una densidad de 36.2 habitantes por kilómetro cuadrado.

El número de habitantes es un elemento importante respecto a la multiplicación del coronavirus, pero China con una población 11 veces superior a la de México, tenía al final de 2020 menos de 5,000 muertes por Covid.

En el Mundo no ceden los contagios. El 2 de abril el planeta llegó al primer millón de contagios; el 16 de abril, al segundo millón; el cuarto millón, el 12 de mayo; el octavo millón, el 18 de junio; los 16 millones, el 28 de julio; los 32 millones, el 27 de septiembre y el 3 de diciembre, llegamos a 64 millones de contagios y el 23 de diciembre, se estimaron 77.7 millones de contagios y 1.7 millones de muertos por SARS-CoV-2.

\section{Conclusiones}

1. En nuestro país, hasta el 23 de diciembre del 2020, la cifra de contagios confirmados fue de 1'338,426 y el número de muertes fue de 119,495 defunciones por Covid-19. Los contagios siguen aumentando y las muertes también. La epidemia sigue sin control en México y en el planeta. En esta fecha hubo 12,511 casos confirmados y 897 muertes en un día. Las vacunas empezaron a llegar a finales del 2020. Esta fue una luz que nos permite ver la salida a esta pandemia.

2. El número reproductivo básico o índice de contagiosidad tuvo como máximo el valor de dos a mediados de abril. A partir de ese momento venía bajando a un ritmo lento, con oscilaciones para luego mantenerse constante y volver a incrementarse levemente por arriba de uno.

3. Hasta ahora no ha sido ni será tan letal el Covid-19 como la "Influenza Española" de 1918. En el caso de que el Covid-19 tuviera la misma letalidad que la "Influenza Española" ocurrida en 1918, de 35 muertos por influenza por cada mil habitantes, México podría llegar a casi 4.5 millones de muertos por esta pandemia, cifra que no es posible por las acciones tomadas para enfrentar esta enfermedad, sobre todo al principio de la pandemia.

4. Todavía no podemos decir que la enfermedad cedió, el valor de $R_{0}$ es mayor que 1. La meta es llegar a uno o a menos de uno, para que un enfermo no contagie a otro. Este tipo de indicador habría que calcularlo a nivel de entidad federativa y por municipio, y en determinadas áreas de altos niveles de contagios, principalmente en la zona metropolitana de 
la ciudad de México, lugar de muy alto nivel de contagios y muertes.

5. Es importante reconocer que las medidas tomadas por el gobierno coadyuvaron a que el número reproductivo básico nunca alcanzara cifras superiores a dos, sin embargo, el descenso ha sido muy lento para llegar a $R_{0}=1$ y en últimas fechas vuelve a crecer.

6. La evolución de las defunciones por Covid-19 siguió un comportamiento exponencial hasta mediados de agosto y partir de esa fecha empezó descender. Como dicen ahí la curva se dobló, es decir, llegó a su punto de inflexión. En la segunda semana de octubre empezó nuevamente a incrementarse.

7. Es importante señalar que el mensaje de "Susana distancia" fue positivo, el número de muertes y contagios hubiera sido mayor, sin embargo, hoy es insuficiente, por lo que es necesario redoblar esfuerzos para que el número reproductivo básico no se incremente y siga descendiendo. A "Susana distancia" ya la jubilaron. Hay que reconocer que fue un instrumento de comunicación muy efectivo para enfrentar la pandemia.

8. Esta pandemia nos deja una experiencia a la población y a los gobernantes de los países. Debemos cuidar el planeta, porque en cualquier momento puede ocurrir una catástrofe que pueda llevar a la extinción de la raza humana. La globalización ha sido todo un éxito, pero así como se han incrementado las relaciones comerciales entre los países del planeta, también se han globalizado los contagios de enfermedades. Es importante hacer caso a quienes conocen del tema. Los políticos han mostrado una tremenda ignorancia, con la agravante de que no corrigen cuando ven que sus políticas fallan.

9. En 2020, la esperanza de vida al nacer en México se reducirá de 75 años de vida a niveles semejantes a los observados a fines del siglo $\mathrm{XX}$, tanto por los homicidios ocurridos en el año, como por las muertes atribuibles al SARS-CoV-2. Estas dos décadas del siglo XXI recibirán el nombre de las décadas perdidas respecto a la disminución en los niveles de mortalidad.

10. El Estado Mexicano ha debido dirigirse con claridad a la población. Es importante no enviar mensajes contradictorios. Deben darse mensajes contundentes y claros. El tema del tapabocas ha sido muy discutido y ha confundido a la población. La autoridad máxima de un país debe poner el ejemplo. Si la población observa que las autoridades no usan el tapabocas, los individuos imitarán esas acciones, sobre todo si los funcionarios son altamente reconocidos. 
11. Las instituciones encargadas de producir y analizar información demográfica deben pasar de observadoras a actoras. Nuevos métodos de generación de información con Big Data deberán empezar a producirse en las instituciones nacionales de estadística. No es posible esperar meses para tener datos que se necesitan en tiempo real para enfrentar un problema como el que hoy nos aqueja. Haciendo una analogía, nuestros sistemas de información son como si quisiéramos sacar una fotografía a un avión que pasa a unos metros enfrente de nosotros a la velocidad del sonido. No veríamos nada.

12. Esta pandemia también nos presenta diferencias por género en relación a la forma distinta de actuar en esta situación como esta, entre hombres y mujeres. La aparente resistencia de los hombres a usar el cubrebocas, ¿pudiera explicarse por un estereotipo de género? ¿El machismo se encuentra detrás de esta conducta?

13. La mortalidad por SARS-CoV-2 está afectando más a las personas de edades avanzadas y principalmente a los hombres. Por sexo también hay diferencias. Como dijimos, en México de cada tres muertes, dos son de hombres. Desde un punto de vista biológico la mujer es más fuerte que el hombre. Esto se constata también observando que la esperanza de vida al nacer es mayor en las mujeres que en los hombres, aproximadamente unos cinco años. Además, el coronavirus se ha ensañado con las personas pobres que habitan las zonas marginadas de las zonas metropolitanas. Si además observamos que la mortalidad por homicidios es mayor en la población masculina, y que la mortalidad por Covid también es mayor entre los hombres, al final de la vida muchas mujeres vivirán sin sus parejas, enfermas, sin ingresos y sin seguridad social. Urge tener un plan actuarial para enfrentar este problema demográfico que afectará principalmente a la población femenina.

14. La pandemia del SARS-CoV-2 en México, y seguramente en otras partes del planeta, tendrá efectos en sus componentes demográficos. El número de matrimonios se reducirá en el año, y en consecuencia bajará el nivel de la fecundidad, por lo que se reducirá el número de hijos. Las parejas decidirán no casarse hasta no ver el fin de la enfermedad. Los niveles de la mortalidad aumentarán significativamente como resultado de las defunciones por SARS-CoV-2, lo que traerá una importante reducción en la esperanza de vida al nacer.

15. Al estar por terminar este artículo a finales de 2020 puedo señalar que el SARS-CoV-2 no se ha controlado, los contagios son muy elevados y las muertes también. Han llegado las primeras vacunas y esperamos 
todos que la logística de distribución y de su aplicación a la población sea exitosa.

16. Lo incierto de los datos, debido a que no conocemos el grado de omisión de los contagios y de las muertes por Covid-19 que ocurren día con día hace que tengamos muchas preguntas sin respuesta. Esto se debe a que nuestros sistemas de generación de datos y muchos de nuestros métodos no están construidos para analizar eventos que ocurren a una gran velocidad, como ha ocurrido en esta pandemia.

\section{REFERENCIAS BIBLIOGRÁFICAS}

Arellano González, Carlos, 2020, "Y un siglo después, el jinete del apocalipsis volvió. La 'gripe española' en México", en Milenio 2020, México, disponible en milenio.com/cultura/gripe-espanola-1918-mato-miles-mexico, recuperado el 14/04/2020.

de Kruif, Paul, 2014, Los cazadores de microbios. Editorial Porrúa, "SEPAN CUANTOS...", número, 637, México.

Defoe, Daniel, 1722, A journal of the plague year, Reino Unido.

Gates, Bill, 2020, El Ágora diario del agua.

Graunt, John, 1662, Natural and Political Observations Mentioned in a Following Index, and Made upon the Bills of Mortality.

Jerome Walters, Mark, 2011, Seis plagas modernas y como las estamos ocasionando. Fondo de Cultura Económica, Colección Popular, 703. Traducción de la primera edición en inglés de 2003.

Lotka, Alfred J., 1969, Teoría Analítica de las Asociaciones Biológicas. CELADE, Santiago de Chile.

Malthus, Thomas Robert, 1977, Ensayo sobre el principio de la población. Fondo de Cultura Económica, México. Sección de Obras de Economía. La primera edición en inglés se publicó en 1798.

Ministerio de Sanidad, 2020, Información cientifica-técnica. Enfermedad por coronavirus, Covid-19; España.

Reinhard, Marcel y Armengaud, Andre, 1966, Historia de la Población Mundial, Ediciones Ariel, Barcelona.

Sagan, Carl, 1998, Miles de millones. Liberdúplex, S.L. Barcelona,

Ventura, Dalia, 2020, BBC News Mundo. Disponible en https://www.bbc.com/ mundo/noticias-52008703, recuperado el 4/04/2020. 


\section{RESUMEN CURRICULAR DEL AUTOR}

\section{Manuel Ordorica Mellado}

Actuario de la Facultad de Ciencias de la Universidad Nacional Autónoma de México (UNAM); maestro en demografía de El Colegio de México y doctor en Investigación de Operaciones en la UNAM. Realizó una especialidad en Análisis Demográfico en la Agencia de Cooperación Internacional de Japón. Fue jefe de Evaluación Demográfica en la Dirección General de Estadística y director de Estudios de Población en el CONAPO; consultor en Educación en Población en la UNESCO. Coordinó la Maestría en Demografía y el Doctorado en Estudios de Población en El Colegio de México. Fue Director y Secretario General en el mismo Colegio. Formó parte del Consejo Editorial de la revista Population del INED en París. Fue miembro del Comité técnico para la Redistritación y para la Evaluación del Padrón Electoral en el INE. Pertenece al Sistema Nacional de Investigadores nivel III. En 1998 recibió el Premio Nacional de Demografía. Realizó una estancia sabática en el CentroGeo de Conacyt. Actualmente es profesor-investigador de El Colegio de México y trabaja en demografía matemática. En 2015 se publicó en la revista Coyuntura Demográfica el artículo: En Ciudad Juárez los hombres se mueren también y su esperanza de vida se reduce. En la misma revista, en 2018, se publicó el artículo: Estimaciones de la población de áreas pequeñas desde la Tierra como del Cielo. El caso de Tenosique. En 2016 se publicó su libro sobre los Grandes Problemas: Una mirada al futuro demográfico de México, editado por E1 Colegio de México y la UNAM. En 2017 Springer publicó el artículo: Estimación de la población de áreas pequeñas a través del Filtro de Kalman. Dirección electrónica: mordori@colmex.mx

Registro ORCID: https://orcid.org/0000-0002-7649-1729 